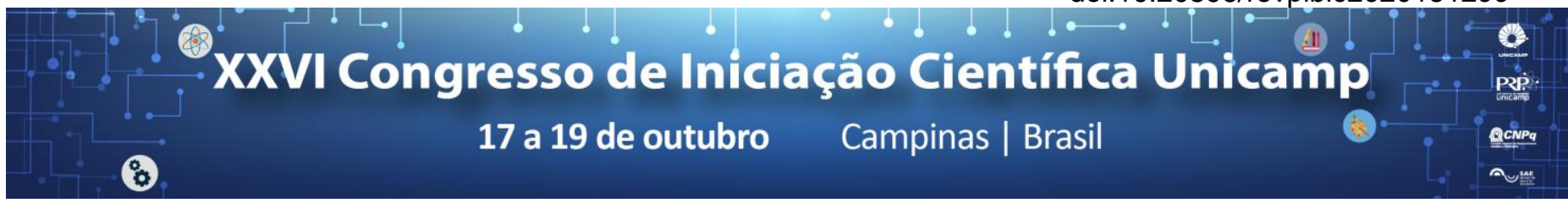

\title{
Production of functional cookies enriched with flour apple industries and apple peel (Malus domestica Borkh).
}

\section{Thaís de Almeida*, Maurício A. Rostagno, Laise Capelasso da Silva.}

\begin{abstract}
This project proposed the study of the best means of extracting bioactive compounds present in the apple peel, from the industrial residues, and its application for the elaboration of cookies with functional properties. To this end, a dry extract of apple peel and industrial by-product was made by freeze-drying to replace wheat flour of the traditional formulation in different concentrations $(2.5 \%, 5 \%, 7.5 \% 10 \%)$, analyzing the thermal stability of the compounds by comparing the raw and roasted mass. The extracts obtained were evaluated for total phenol content using the Folin-Ciocalteu (FT) reagent method, the antioxidant activity (AC) by the FRAP and ABTS method and the Liquid Chromatography (HPLC) analysis. The results showed that Extract of the by-product presented a higher concentration of total phenolics and antioxidant activity than the flour from the apple peel, as well as the stability of the compounds after cooking.
\end{abstract}

\section{Key words:}

Apple, bioactive compounds, purification, functional food.

\section{Introduction}

Apple is one of the most consumed fruits in the world and its industrial use generates waste that is discarded and this byproduct is rich in bioactive compounds such as flavonoids (Rutin and Phloridzin), flavonols (catechin and epicatechin) and phenolic acids ( chlorogenic acid and gallic acid) (1). These compounds may decrease oxidative damage, disfavoring the incidence of degenerative diseases, and help delay early aging (2).

The main objective of the study was to develop a powder extract from the reuse of the by-product and its application in a food matrix.

\section{Results and Discussion}

It was verified that the extractions made on the same conditions of temperature, time and solvents had different responses, indicating a greater amount of bioactive compounds in the flour of the industrial residues, when compared to the flour made from the apples in natura. The results indicate that among the concentrations $(2.5 \%, 5 \%, 7.5 \%, 10 \%)$ the cookie with the highest percentage of enrichment, offered a greater response in relation to the others.

The extraction temperature was 50 to $60 \circ \mathrm{C}$ using a combination of $\mathrm{H} 2 \mathrm{O}$ and $\mathrm{meOH}$.

Image 1. Total phenolic compounds.

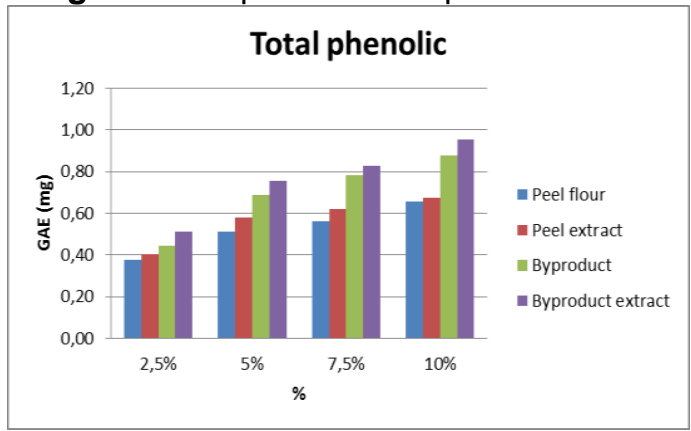

Image 2. Antioxidant capacity by the FRAP method.

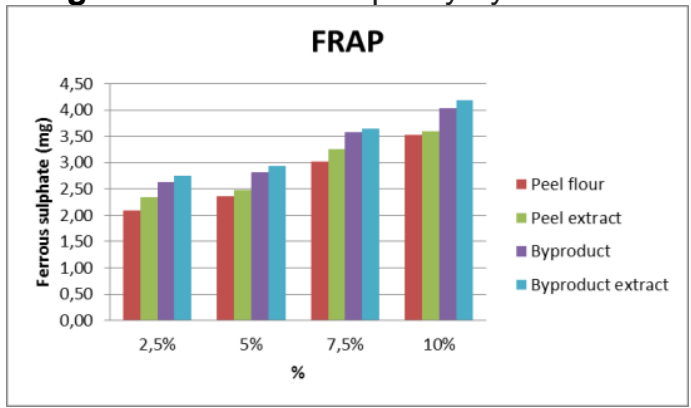

Image 3. Antioxidant capacity by the ABTS method.

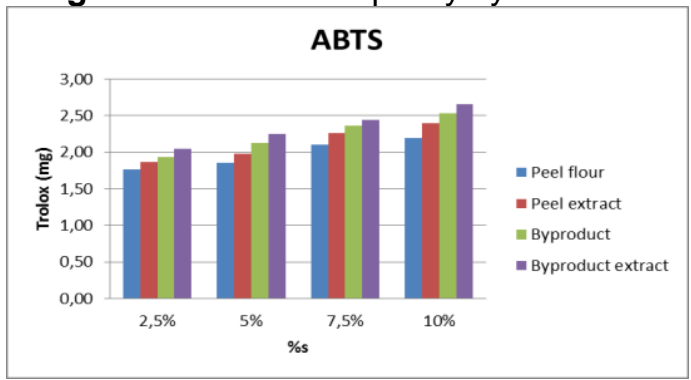

\section{Conclusions}

From the initial analyzes it was possible to conclude that there is a significant increase of bioactive compounds with the incorporation of the flour, being the cookie with the flour of the extract of the byproduct which showed greater results of both FT and CA, however more studies are necessary.

\section{Acknowledgement}

Thanks to PIBIC, laboratory LAPFAL, FCA and Maurício A. Rostagno.

\footnotetext{
1 PIMENTEL, C. V. M. B. F., V. M.; GOLlÜCKE, A. P. B. Alimentos funcionais: introdução as principais substâncias bioativas em alimentos. São Paulo: Ed. Varela. p. 95, 2005

${ }^{2}$ SOARES, M. et al. Avaliação da atividade antioxidante e identificação dos ácidos fenólicos presentes no bagaço de maçã cv. Gala. Ciência e Tecnologia de Alimentos, v. 28, n. 3, p. 727-732, 2008
} 